\title{
TOWARDS A HIGH-RESOLUTION SCATTEROMETER WIND PRODUCT
}

\author{
Ad Stoffelen, Hans Bonekamp, Jeroen Beysens, Jos de Kloe, Marcos Portabella, \\ Anton Verhoef, Jeroen Verspeek
}

KNMI, Postbus 201, 3730 AE De Bilt, the Netherlands. Email: Ad.Stoffelen@KNMI.nl.

\begin{abstract}
In Europe, scatterometer product development is organised through the EUMETSAT Satellite Application Facilities. SeaWinds developments are focussed on using the data for Numerical Weather Prediction and short-range weather forecasting. The former is well suited by the products as currently produced at KNMI at 100-km resolution (see http://www.knmi.nl/scatterometer/qscat prod). For short-range forecasting or in semi-enclosed sea areas such as the Mediteranean, however, higher resolution is desirable. KNMI attempts to improve the spatial filtering properties of the wind retrieval by using prior information on the expected meteorological balance, e.g., favouring rotational structures in high-latitude regions. Moreover, we use solutions in all wind directions, but weighted by their inherent probability.

We anticipate that the 2D-VAR method has the advanced filtering properties for maintaining small-scale meteorological information in SeaWinds, while reducing noise. This is tested by comparing the spatial covariance structures of the KNMI products, with those of the NOAA SeaWinds product, and, for reference, those of the ECMWF model. The methodology leads towards a high-resolution scatterometer wind product.
\end{abstract}

\section{INTRODUCTION}

The all-weather capability of a scatterometer provides unique wind field products of the most intense and often cloud-covered wind phenomena, such as tropical cyclones (for example, see figure 1). As such, it has been demonstrated that scatterometer winds are useful in the prediction of tropical cyclones, e.g., Isaksen and Stoffelen (2000), and extra-tropical cyclones (Stoffelen and Beukering, 1997). At the moment the ESA ERS-2 and the NASA SeaWinds scatterometer on QuikScat provide respectively a regional real-time and a global near-real time data stream. In 2005 EUMETSAT will continue the global scatterometer mission with the ASCAT scatterometer on EPS/METOP, and will start a regional real-time ASCAT dissemination. As such, continuity of both services is likely provided to the operational meteorological community for another period of 15 years.

EUMETSAT set up Satellite Application Facilities (SAF) providing software and data products and services. $\mathrm{KNMI}$ is involved in the scatterometer activities of the following SAFs in preparation for ASCAT:

- Numerical Weather Prediction SAF for scatterometer software products;

- Ocean and Sea Ice SAF for scatterometer wind products; and

- Climate SAF for Scatterometer Ocean Stress (SOS) products. 


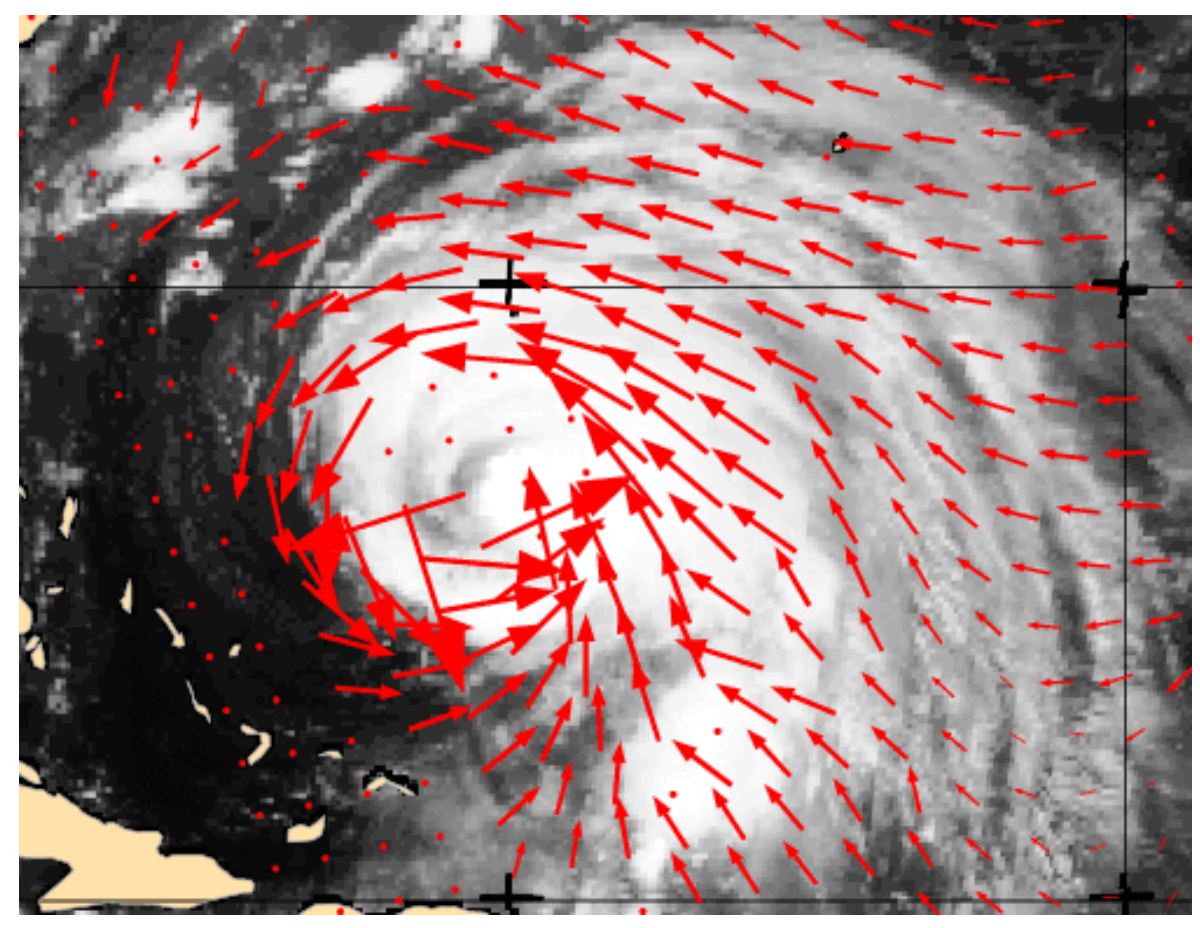

Figure 1. QuikScat SeaWinds $100-\mathrm{km}$ wind product generated at KNMI for tropical cyclone Isabel (2003), raging in the Caribbean. GOES IR cloud imagery is provided underneath for reference.

Scatterometer sea surface wind research and development lies at the basis of these products:

- Input product consistency checks, quality control, rain (for SeaWinds) and ice (for ERS) screening;

- Simultaneous processing of multiple ERS-2 ground station acquisitions in order to

- provide unique processing at all wind vector cells (WVC), i.e., avoid duplicates;

- complete backscatter triplets by combining acquisitions of all available ground stations at each WVC;

- Spatial averaging methodologies to reduce noise and enhance quality of SeaWinds products;

- Inversion: computation of optimal wind solutions and associated probabilities from measurement information;

- Determination of information content; definition of observation operator; ambiguity removal (spatial filter to determine a unique wind vector field);

- Processors for real-time and archive scatterometer wind and stress products;

- Active monitoring and quality assurance methodologies (of instrument and processing); and

- Web site (visualisation) and product distribution;

Product enhancement and the preparation of wind production and user services for ASCAT on METOP are the main goals of this R\&D. KNMI currently processes a global QuikScat $100-\mathrm{km}$ product and a NorthAtlantic ERS-2 25-km product, and distributes it to the international meteorological community. Moreover, at http://www.knmi.nl/scatterometer links to the visual presentation of these products are provided. Global maps of wind speed are provided over the last 22 hours (as in Figure 2), segregated in ascending and descending orbit tracks. By mouse clicks on these maps more detailed regional plots become available (as in Figure 1). The link also provides documentation, papers, and software products. 


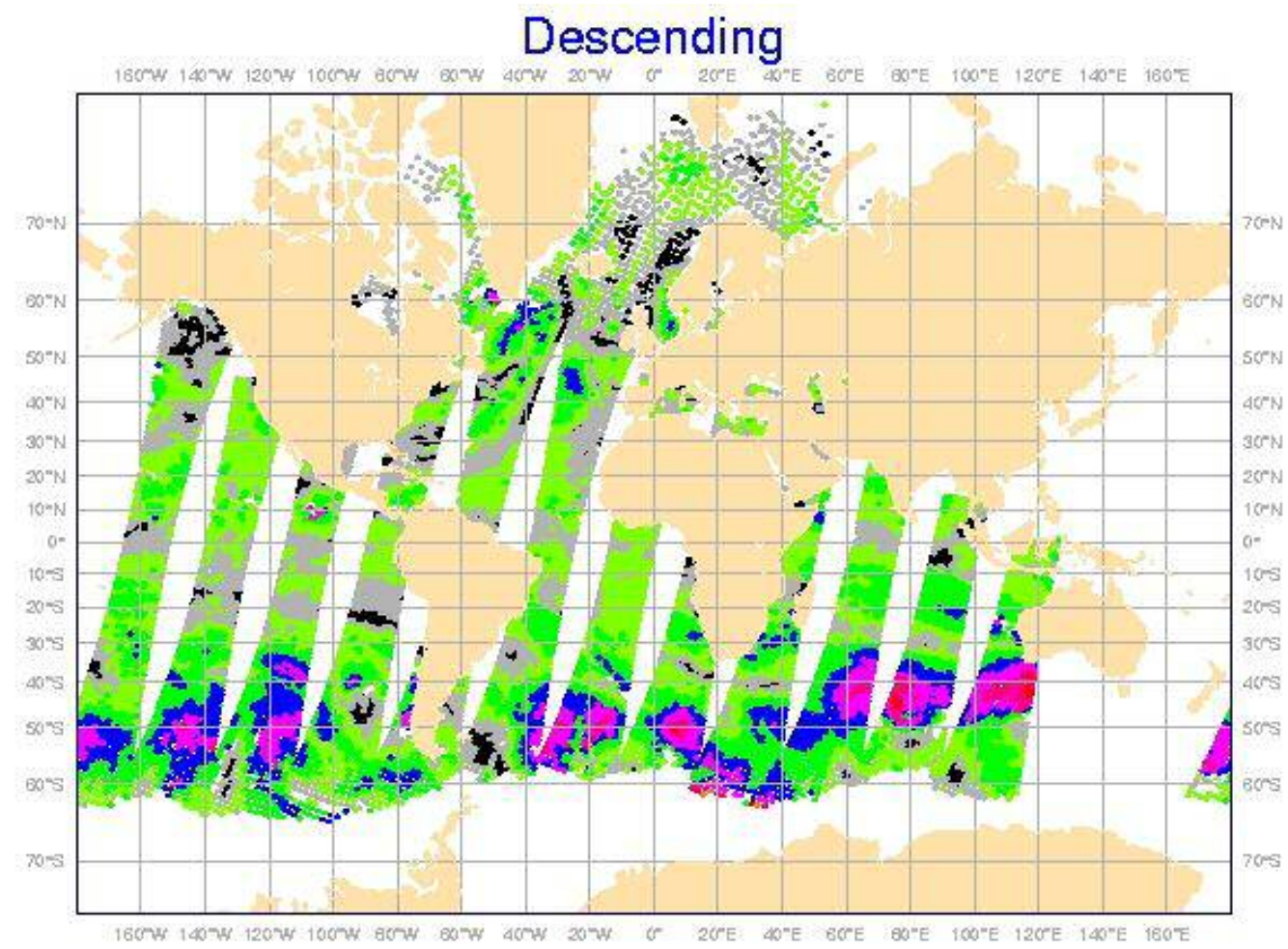

Figure 2. Overview of QuikScat SeaWinds $100-\mathrm{km}$ wind speeds (coloured) as generated at KNMI.

\section{STANDARD QUIKSCAT 100-KM PRODUCT}

The standard KNMI 100-km QuikScat product has been developed for NWP assimilation. A validation is given in table 1. KNMI speeds compare better with ECMWF than NOAA speeds, whereas the wind direction verification is more similar. The noisy wind speeds of NOAA also affect both wind component verifications. Most likely the Direction Interval Retrieval and Threshold Nudging method applied by NASA causes the wind speed noise (Portabella, 2002). Moreover, this scheme results in rather smooth wind direction fields, thus providing a wind direction verification similar to the KNMI 100-km product. The use of the KNMI 100-km product in NWP provides positive or neutral impact, depending on the study period. Further noise reduction and QC is believed to be beneficial for NWP impact and further progress is being made. The former may be achieved by less arbitrary wind vector solution selection after the inversion step.

\begin{tabular}{|c|c|c|}
\hline SD & KNMI & NOAA \\
\hline Speed & 1.31 & 1.64 \\
\hline Direction & 13.58 & 14.58 \\
\hline $\mathrm{U}$ & 1.60 & 1.96 \\
\hline $\mathrm{V}$ & 1.58 & 1.80 \\
\hline
\end{tabular}

Table 1. KNMI QuikScat $100-\mathrm{km}$ wind product and collocated NOAA 25-km product as verified with independent ECMWF first-guess winds at $10 \mathrm{~m}$. The standard deviation (SD) of difference for both products is given (both have small mean bias). 


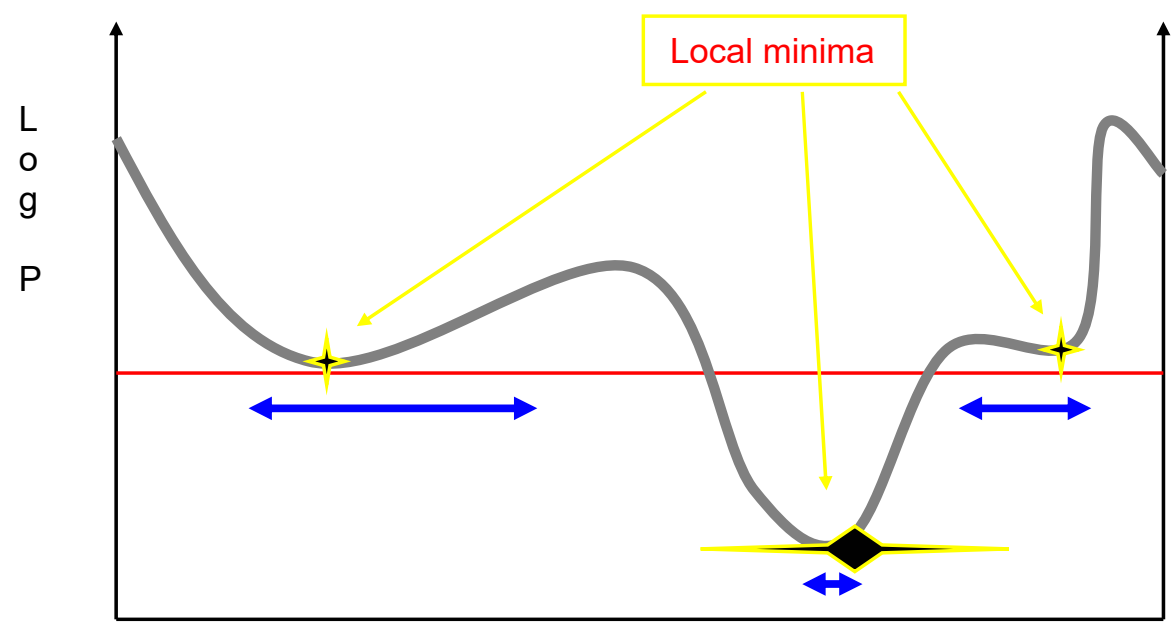

Wind direction $(\phi)$

Figure 3. Schematic of wind direction probability (logarithm) in a scatterometer Wind Vector Cell (WVC). In wind direction occasionally broad solution minima exist not well represented by the local minimum. In wind speed minima are generally sharp.

\section{MULTIPLE SOLUTION SCHEME}

Portabella and Stoffelen (2003) have shown that the KNMI 100-km product can be improved by more fully exploiting the probability information (see table 2), which is implicitly provided by the wind inversion procedure (see figure 3 ). They represented broad wind solution minima by multiple solutions, denoted multiple solution scheme (MSS).

\begin{tabular}{c|ccc} 
Swath region & $\begin{array}{c}\text { Standard } \\
\text { procedure }\end{array}$ & MSS & NCEP \\
\hline Sweet & 2.48 & 2.23 & 2.85 \\
Nadir & 2.98 & 2.45 & 2.96
\end{tabular}

Table 2. Standard QuikScat SeaWinds $100-\mathrm{km}$ wind product and collocated MSS $100-\mathrm{km}$ product as verified with independent ECMWF first-guess winds at $10 \mathrm{~m}$. The wind vector RMS of difference for both products is given.

The table shows the beneficial working of MSS, in particular in the nadir swath, but also elsewhere. Note that Table 2 is produced over a different time period than Table 1 and by keeping some more winds in meteorologically relevant dynamical situations (Portabella and Stoffelen, 2002). The NCEP 1000-mb wind background used for ambiguity removal does not play an important role in the verification, but the improvement is brought by using probability information in combination with the 2D-VAR background constraints on rotation and divergence (Portabella and Stoffelen, 2003). We further note that the improved verification of MSS is mainly due to the reduction of occasional erratic noise; coherent mesoscale structures remain present and become more visible due to the noise reduction. 

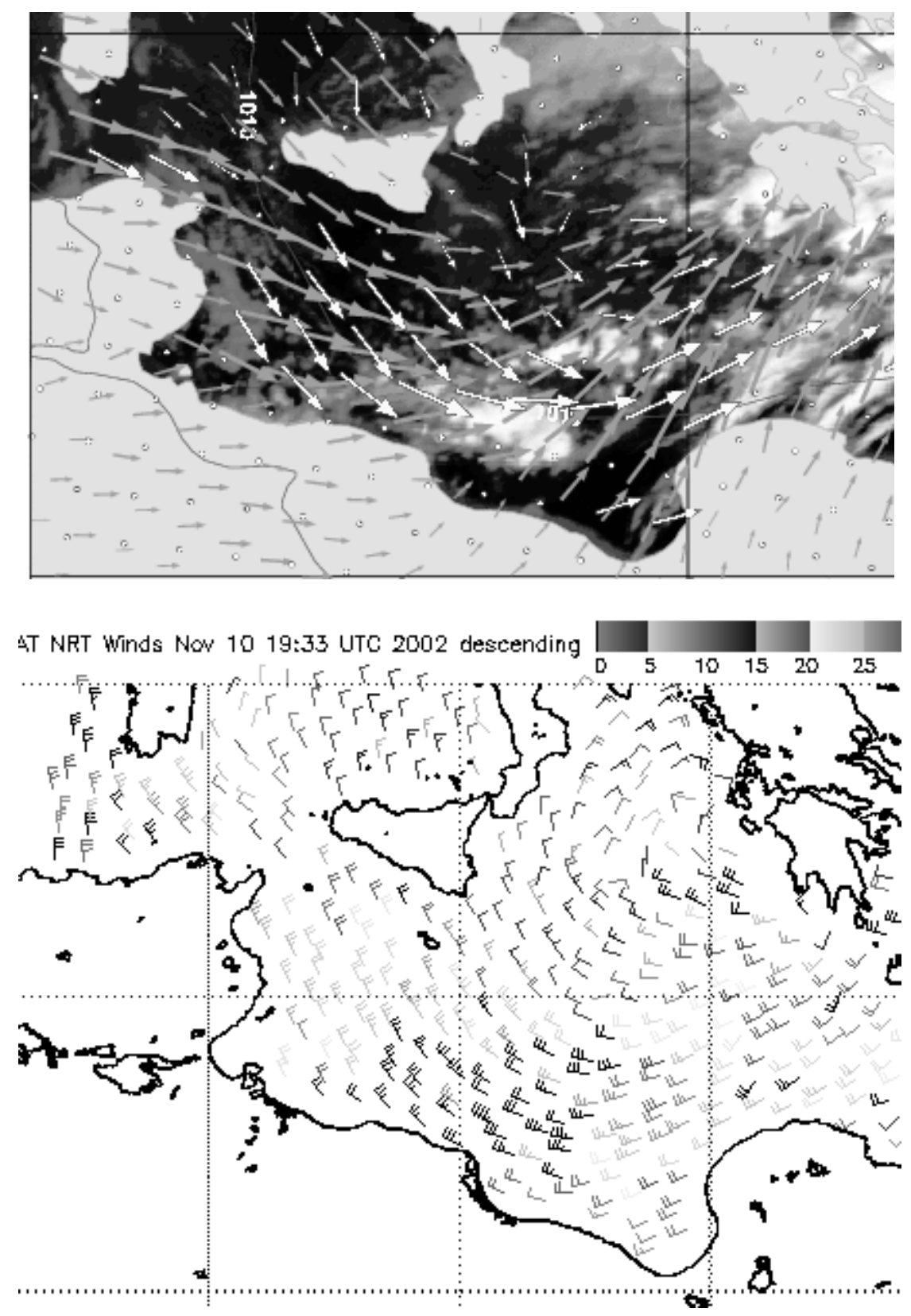

Figure 4: Top: KNMI 100-km SeaWinds product in the Mediteranean (white) and corresponding NWP model winds (grey) on top of a MeteoSat IR cloud image showing a low. SeaWinds winds range from WNW to $\mathbf{N}$ in the upper left.

Bottom: Same as at the top, but NOAA DIRTH SeaWinds product, which shows a smoother wind direction field than KNMI. Note e.g. now the winds are from NW to $N$ in the upper left. The $N$ winds at the far right are in the outer swath and inconsistent with in situ surface data (not shown). On the other hand, NOAA DIRTH shows more coastal winds than KNMI due to the $\mathbf{2 5} \mathrm{km}$ swath grid (Discard a few isolated black flags that are rejected, but shown). 


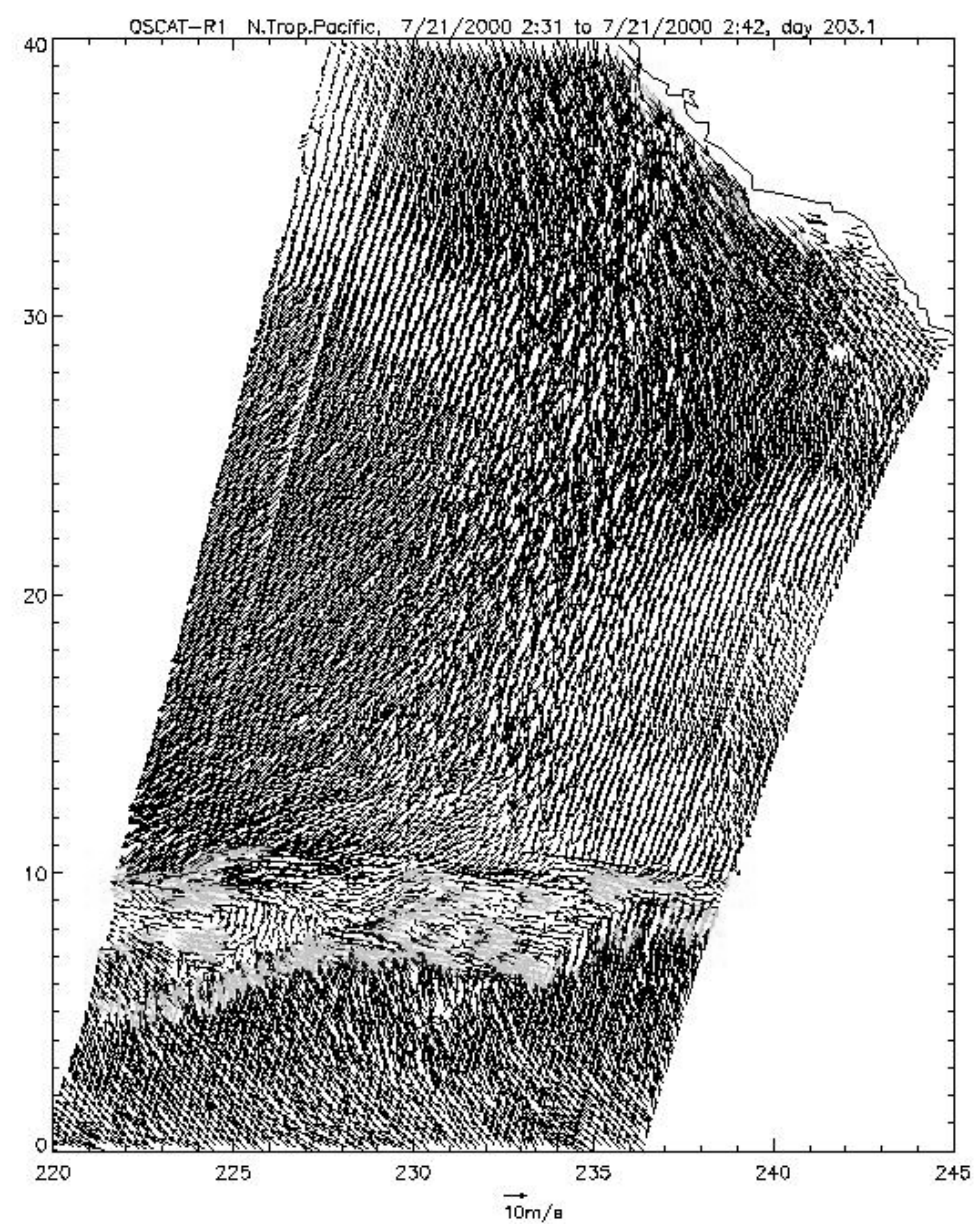

Figure 5: Sample archive SeaWinds product of JPL at 25-km resolution. A $1400-\mathrm{km}$ wide central swath can be seen that is viewed by the inner and the outer beam of SeaWinds. Two outer swath strips of $200 \mathrm{~km}$ are visible that are viewed only by the outer beam. In the middle (nadir) region excessive noise is visible, which is due to the poorer azimuth sampling in this area. In a horizontal area at around $10 \mathrm{~N}$ grey areas denote rain contamination as flagged by JPL (SeaWinds, 2004).

\section{INCREASED SPATIAL RESOLUTION}

Figure 4 shows an example of a Mediteranean wind field as depicted by the KNMI High-Resolution LAM (HiRLAM), the 100-km KNMI SeaWinds product (top), and the NOAA DIRTH product (bottom). It illustrates the smooth wind direction field of the latter and some wind direction ambiguity removal problem in the outer swath at the left. On the other hand the NOAA product shows more coastal winds due to its processing at 25 $\mathrm{km}$.

For many applications in the Mediteranean both coastal winds and high-resolution winds would be particularly useful. However, many researchers documented the non-uniform noise properties of SeaWinds (e.g. COAPS, 2004); see also Figure 5. To obtain more uniform noise properties spatial filtering of SeaWinds data is required. Moreover, from the comparison above it may be clear that coastal winds may be obtained by using a $25-\mathrm{km}$ grid. Rather than statistically filtering median wind direction intervals, such as in DIRTH, a more meteorologically balanced way of spatial filtering should be sought.

\section{OUTLOOK}

KNMI developed a spatial filtering method that fully exploits the information obtained by scatterometer wind retrieval (Portabella and Stoffelen, 2003) and which is meteorologically balanced, called MSS. Given the beneficial working of MSS, an increase in the resolution of the QuikScat wind retrieval may be feasible. For this purpose, the scatterometer wind retrieval software is adapted, and the occurrence of systematic effects 
in the wind retrieval investigated. MSS is expected to work better than a statistical (median) filter such as DIRTH. The KNMI 25-km version of MSS will become available in early 2005 for the user community. It will be verified spatially by correlation analyses and against in situ observations. KNMI welcomes potential users and testers of this product, whom should contact the author.

Scatterometers provide accurate and spatially consistent near-surface wind information. Hardware permitting, there will be a continuous series of scatterometers with at times ideal coverage of the ocean surface wind for the first two decades of this century. EUMETSAT provides user services in collaboration with KNMI, where these are now being set up and freely available at http://www.knmi.nl/scatterometer for the QuikScat and ERS-2 scatterometers. Near-real time FTP products or software can be obtained after registration. Moreover, a visiting scientist scheme is funded in order to support the development programme and the use of the KNMI services. Again, the authors will provide more information on request.

\section{REFERENCES}

Portabella, M., Stoffelen, Ad, (2003) MSS.

Atlas, R., and R.N. Hoffman (2000), The Use of Satellite Surface Wind Data to Improve Weather Analysis and Forecasting, in Satellites, Oceanography, and Society, edited by D. Halpern, Elsevier Oceanography Series 63, Elsevier Science, Amsterdam, the Netherlands, ISBN 0-444-50501-6.

COAPS, 2004, COAPS home page with SeaWinds animations/characterisation, http://coaps.fsu.edu/ bourassa

ECMWF (2004) European Centre for Medium-range Weather Forecast, http://www.ecmwf.int

EUMETSAT Satellite Application Facilities (SAF) (2004), http://www.eumetsat.de/saf

HiRLAM (2004) High-Resolution Limited Area Model, http://hirlam.knmi.nl

Isaksen, Lars, and Ad Stoffelen, (2000) "ERS-Scatterometer Wind Data Impact on ECMWF's Tropical Cyclone Forecasts", IEEE-Transactions on Geoscience and Remote Sensing (special issue on Emerging Scatterometer Applications) 38 (4), pp. 1885-1892.

KNMI (2004) http://www.knmi.nl/scatterometer

Portabella, Marcos, and Ad Stoffelen, (2001) Rain detection and quality control of SeaWinds. J. Atm. and Ocean Techn. 18 (7), pp. 1171-1183.

Portabella, Marcos, and Ad Stoffelen, (2003) A probabilistic approach for SeaWinds data assimilation," Quart. J. R. Met. Soc. 130, pp. 127-159.

SeaWinds (2004)

Instrument: http://winds.jpl.nasa.gov/missions/quikscat/quikindex.html

Archive data: http://podaac.jpl.nasa.gov/quikscat

Near-real time data: http://manati.wwb.noaa.gov/quikscat

Stoffelen, Ad, (2000) A generic approach for assimilating scatterometer winds, proc. ECMWF seminar 4-8 Sept. 2000, available from http://www.knmi.nl/scatterometer/seawinds/pdf/ECMWF seminar00.pdf.

Stoffelen, Ad, Aart Voorrips, and John de Vries, (2000) Towards the Real-Time Use of QuikScat Winds, BCRS project report, available from KNMI.

Stoffelen, Ad, and Paul van Beukering, (1997) The impact of improved scatterometer winds on HIRLAM analyses and forecasts, BCRS study contract 1.1OP-04, report published by BCRS, Delft, The Netherlands, and HIRLAM technical report \#31, published by IMET, Dublin, Ireland. Available from KNMI.

REMSS, (2004) Remote Sensing Systems homepage with off-line SeaWinds products, http://www.remss.com 